Research, part of a Special Feature on Heterogeneity and Resilience of Human-Rangifer Systems: A CircumArctic Synthesis

\title{
Seasonal Climate Variation and Caribou Availability: Modeling Sequential Movement Using Satellite-Relocation Data
}

\author{
$\underline{\text { Craig Nicolson }}^{1}, \underline{\text { Matthew Berman }}^{2}, \underline{\text { Colin Thor West }}^{3}, \underline{\text { Gary P. Kofinas }}^{4}, \underline{\text { Brad Griffith }}^{5,6}, \underline{\text { Don Russell }}^{7}$ and Darcy Dugan $^{8}$
}

ABSTRACT. Livelihood systems that depend on mobile resources must constantly adapt to change. For people living in permanent settlements, environmental changes that affect the distribution of a migratory species may reduce the availability of a primary food source, with the potential to destabilize the regional social-ecological system. Food security for Arctic indigenous peoples harvesting barren ground caribou (Rangifer tarandus granti) depends on movement patterns of migratory herds. Quantitative assessments of physical, ecological, and social effects on caribou distribution have proven difficult because of the significant interannual variability in seasonal caribou movement patterns. We developed and evaluated a modeling approach for simulating the distribution of a migratory herd throughout its annual cycle over a multiyear period. Beginning with spatial and temporal scales developed in previous studies of the Porcupine Caribou Herd of Canada and Alaska, we used satellite collar locations to compute and analyze season-by-season probabilities of movement of animals between habitat zones under two alternative weather conditions for each season. We then built a set of transition matrices from these movement probabilities, and simulated the sequence of movements across the landscape as a Markov process driven by externally imposed seasonal weather states. Statistical tests showed that the predicted distributions of caribou were consistent with observed distributions, and significantly correlated with subsistence harvest levels for three user communities. Our approach could be applied to other caribou herds and could be adapted for simulating the distribution of other ungulates and species with similarly large interannual variability in the use of their range.

Key Words: caribou; markovian; migration; Rangifer tarandus granti; seasonal distribution; simulation; subsistence hunting

\section{INTRODUCTION}

Livelihood systems that depend on mobile resources must constantly adapt to change. The livelihood strategy of indigenous nomadic herders, for example, is adapted to the migratory cycle of the species they use (Jernsletten and Klokov 2002). Reindeer herders in the Yamal-Nenets region of western Siberia (Forbes et al. 2009) and Turkana pastoralists of East Africa (McCabe 2004) both move with their herds to maximize the use of different forage resources at different times of year. In contrast, people who live in settlements and harvest migratory resources such as whales or caribou are more vulnerable to changes in the movement and distribution patterns of the species on which they depend. Indigenous peoples in the North American Arctic historically were seasonally nomadic, but were settled in fixed locations during the 20th century (Chance 1966, Burch 1998). For these communities, environmental changes that affect the movements or distribution of major food sources may cause significant hardship and introduce major shocks to the socialecological system (Fienup-Riordan 1986, Burch 2012).

Long-distance migration is common to many taxa (Dingle 1996), and mass ungulate migrations have been described across a wide range of ecosystems (Craighead et al. 1972, Estes 1991, Ito et al. 2006, Harris et al. 2009). Among ungulates, Arctic barren-ground caribou (Rangifer tarandus granti) make one of the longest annual migrations, about 800 to $3000 \mathrm{~km}$ (Fancy et al. 1989), traveling at certain times of year daily distances in excess of $15 \mathrm{~km}$ per day (Griffith et al. 2002). Although caribou movement and distribution have been studied at least since the 1930s (Burch 2012), knowledge of the specific mechanisms remains inadequate to explain and predict seasonal distribution for specific years.

The literature on social-ecological systems emphasizes the embeddedness of humans in nature and calls for analytical approaches situated at the nexus between social systems and ecosystems (Folke 2006, Chapin et al. 2009). The availability of caribou to Arctic communities, for example, is determined both by social and ecological processes (Berman and Kofinas 2004). To assess the vulnerability of social-ecological systems to environmental change, we cannot simply focus on the ecological processes without reference to the social systems to which they are coupled. We examine long-term satellite relocation data for the Porcupine Caribou Herd ( $\mathrm{PCH})$, numbering over 100,000 animals migrating through northeastern Alaska and northwestern Canada. We draw on these data to develop a simulation model for caribou migration that can be used to analyze the local social-ecological system. Our approach for predicting interannual variability in the seasonal caribou herd distribution, and the associated seasonal availability for subsistence hunting, takes into account the

\footnotetext{
${ }^{1}$ Department of Natural Resources Conservation, University of Massachusetts, Amherst, ${ }^{2}$ Institute of Social and Economic Research, University of Alaska Anchorage, ${ }^{3}$ Department of Anthropology, University of North Carolina at Chapel Hill, ${ }^{4}$ Department of Humans and Environment and Institute of Arctic Biology, University of Alaska, Fairbanks, ${ }^{5}$ U.S. Geological Survey Alaska Cooperative Fish and Wildlife Research Unit, ${ }^{6}$ Institute of Arctic Biology University of Alaska Fairbanks, ${ }^{7}$ CircumArtic Rangifer Monitoring and Assessment Network (CARMA), ${ }^{8}$ Alaska Ocean Observing System
} 
path-dependent sequential nature of caribou movement, the role of seasonally varying environmental conditions, and the location of human settlements.

The research addressed four objectives: (1) show that recorded individual movements of caribou can explain both the seasonal distribution of the herd and differences in caribou availability to rural communities among years; (2) test the hypothesis that movement of individuals in the herd responds to seasonal climate variation; (3) simulate the path-dependent sequence of movements that produce seasonal caribou distribution; and (4) link variation in community seasonal harvests to population-level caribou distribution. We began with two hypotheses: (H1) the observed location of an individual animal in a given season affects where it will move in its region during the next season, and (H2) a set of ecological drivers such as snow depth, insect levels, etc., also influence the animal's movements.

\section{STUDY AREA}

The study area encompasses the annual range of the Porcupine Caribou Herd, a region covering $\sim 290,000 \mathrm{~km}^{2}$ in the Northwest Territories, Yukon Territory, and Alaska (Fig. 1). In general, the herd moves from northern coastal calving areas in the spring to southern taiga areas in the winter. Calving tends to coincide with the rapid growth of protein-rich vascular tundra plants, which provide critical forage for lactating cows (Griffith et al. 2002, McNeil et al. 2005). As summer progresses, animals move to coastal zones or mountain ridges where breezes provide some relief from insect harassment (Walsh et al. 1992). Caribou start moving south in August, and rut in early October, wintering in river valleys and slopes in the Ogilvie and Richardson mountains and the southern Brooks Range (Russell et al. 1993, Russell and McNeil 2005). These taiga zones provide energy-rich lichen, which caribou access by digging through snow with their uniquely adapted hooves. Pregnant cows begin the spring migration north toward the coast in March or April.

$\mathrm{PCH}$ are harvested almost exclusively by indigenous hunters from Alaska villages of Kaktovik, Arctic Village, Venetie, and Fort Yukon, as well as from Canadian communities of Old Crow, Fort McPherson, and Aklavik. The approximate annual harvest rate is 2 to $4 \%$ (Hanley and Russell 2000). Harvesting opportunities vary across villages based on their location within the $\mathrm{PCH}$ seasonal migration pattern and the annual variation in this pattern. Arctic coastal communities, Kaktovik and Aklavik, mostly take caribou from late spring to early fall, while interior communities harvest most animals during fall and spring migration. Wolves take an estimated 5.8 to $7.4 \%$ of adult caribou annually, primarily in fall and winter (Hayes and Russell 2000). Fluctuations in herd size appear to be governed more by changes in forage or weather events than by hunting or predation (Griffith et al. 2002, Arthur et al. 2003). During the time period covered by our study, the PCH increased from around 145,000 caribou to 178,000 (1985-1989), then declined to 123,000 by 2001 .

Fig. 1. Study area: the range of the Porcupine Caribou Herd, from Kofinas and Braund (1998:14), divided into ecological movement zones (1-13) and subzones (dashed lines within zones).

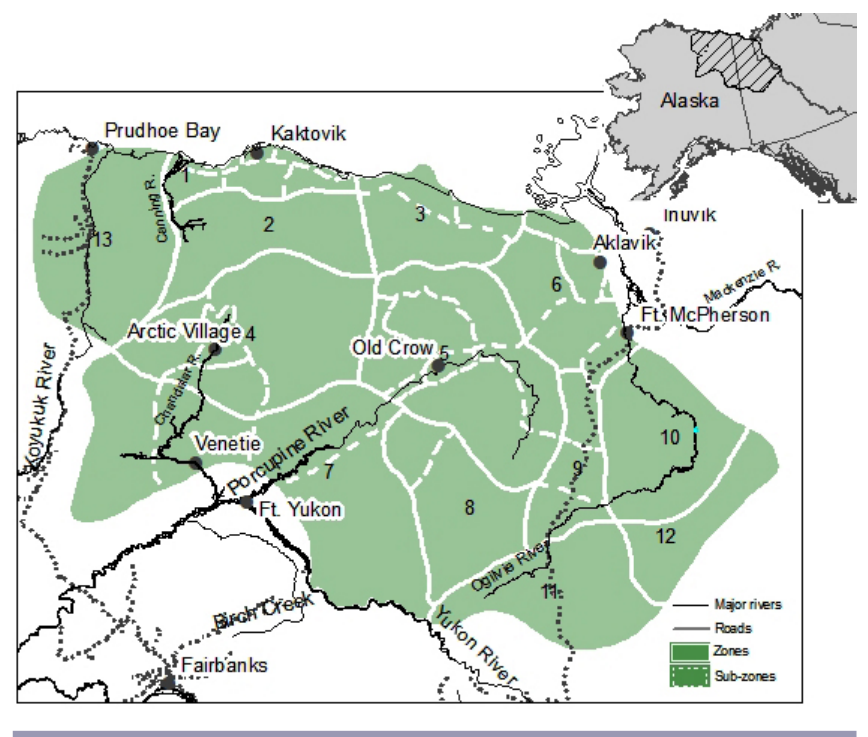

\section{METHODS}

\section{Satellite collar locations, 1985-2003}

Satellite collars were first deployed on Porcupine Caribou in 1985. A cooperative arrangement between several Canadian and U.S. government agencies funded the placement and data retrieval costs of between 8 and 25 collars each year from 1985 to July 1995, when the program was ended because of financial constraints. In October 1997 a new satellite-collaring program restarted and 10 cows were collared. This program continued through 2003 with the goal of maintaining at least 7 collared cows each year. From April 1985 to December 2003, a total of 68 individual animals were collared, providing 23,670 satellite collar locations. Frequency of location data varies across years and seasons, and across individual animals (Table $1)$.

Since the 1980s, satellite collars have provided rich datasets tracking the movement of individual animals, and a long-term dataset exists therefore to develop and validate models of caribou movement and distribution. Eastland (1991) used this dataset to map the herd's fall distribution, and used dietary intake to explain their proximity to the community of Old Crow, one of the PCH user communities. Griffith et al. (2002) correlated annually varying collar locations during calving with variations in the Normalized Difference Vegetation Index (NDVI), a remote-sensed index of the rate of green-up, 
Table 1. Number of collared animals by season. The eight seasons of a model year run from calving in the calendar year through spring of the following calendar year, i.e., calving in model year 1985 represents June 1985, while spring migration represents April/May 1986.

\begin{tabular}{|c|c|c|c|c|c|c|c|c|}
\hline Caribou movement year & Calving & $\begin{array}{c}\text { Post- } \\
\text { calving }\end{array}$ & $\begin{array}{c}\text { Early } \\
\text { summer }\end{array}$ & $\begin{array}{c}\text { Mid- } \\
\text { summer }\end{array}$ & Early fall & Rut & Winter & Spring \\
\hline 1985 & 8 & 7 & 7 & 8 & 8 & 8 & 7 & 7 \\
\hline 1986 & 5 & 5 & 10 & 5 & 5 & 5 & 8 & 10 \\
\hline 1987 & 10 & 10 & 10 & 11 & 11 & 10 & 15 & 12 \\
\hline 1988 & 16 & 17 & 15 & 14 & 13 & 15 & 13 & 12 \\
\hline 1989 & 20 & 19 & 20 & 21 & 21 & 20 & 17 & 12 \\
\hline 1990 & 10 & 10 & 10 & 8 & 8 & 4 & 4 & 3 \\
\hline 1991 & 5 & 5 & 3 & 3 & 3 & 3 & 3 & 3 \\
\hline 1992 & 12 & 12 & 11 & 11 & 11 & 11 & 10 & 8 \\
\hline 1993 & 8 & 8 & 7 & 8 & 8 & 8 & 8 & 8 \\
\hline 1994 & 7 & 6 & 7 & 6 & 5 & 4 & 4 & 2 \\
\hline 1995 & 1 & 1 & - & 1 & - & - & - & - \\
\hline 1996 & - & - & - & - & - & - & - & - \\
\hline 1997 & - & - & - & - & - & - & 8 & 10 \\
\hline 1998 & 9 & 9 & 8 & 9 & 9 & 7 & 7 & 7 \\
\hline 1999 & 7 & 7 & 6 & 7 & 7 & 7 & 7 & 8 \\
\hline 2000 & 4 & 6 & 6 & 8 & 8 & 8 & 8 & 8 \\
\hline 2001 & 7 & 8 & 8 & 8 & 8 & 8 & 7 & 8 \\
\hline 2002 & 6 & 8 & 8 & 8 & 8 & 8 & 8 & 10 \\
\hline 2003 & 9 & - & - & - & - & - & - & - \\
\hline
\end{tabular}

demonstrating that annual concentrated calving areas were located in areas of high food abundance.

\section{Caribou movement zones and community hunting subzones}

For the spatial scale of our analysis and model, we used nested spatial units originally delineated by Kofinas and Braund (1998), and subsequently refined by Berman and Kofinas (2004). Kofinas and Braund divided the range into 12 large movement zones based on knowledge of seasonal caribou distribution patterns (Russell et al. 1993), as well as on expert local and scientific knowledge of caribou movement (Fancy et al. 1989, Eastland 1991, Russell et al. 1993). Within the 12 large movement zones, local hunters identified and delineated 38 smaller subzones at a scale relevant to their knowledge of the herd and harvesting opportunities (Berman and Kofinas 2004). We added one additional zone and subzone to account for recorded movements outside the 12 zones. Figure 1 illustrates the movement zones and community-specific subzones. Table 2 lists the habitat characteristics and use by communities of each subzone.

\section{Seasonal ecological drivers}

The Arctic Borderlands Ecological Knowledge Coop documented local ecological knowledge of relationships between $\mathrm{PCH}$ caribou movement and seasonal weather (Kofinas et al. 2002). The Sustainability of Arctic Communities Project drew on this local knowledge and science-based research to model social-ecological implications of climate change on caribou availability (Berman and Kofinas 2004, Berman et al. 2004, Kruse et al. 2004). McNeil et al. (2005) showed, using satellite collar data, that variation in climatic conditions can explain part of the seasonal variation in caribou distribution. Their analysis found differences in average seasonal distribution patterns between sets of years with different weather-related environmental conditions, e.g., shallow vs. deep winter snow, or early vs. late spring snowmelt. McNeil et al. (2005) addressed the probability of seasonal presence and absence of caribou in individual zones within the range of the $\mathrm{PCH}$, but did not account for the possibility that caribou presence in a zone one season could be influenced by the distribution of animals in the previous season.

We built on this work and other studies to explore how the temporal sequence of climate outcomes and associated ecological drivers affects interannual variability, or the dynamics of movement between seasons. We defined the appropriate temporal scale for the analysis to match the seasonal activities of caribou that drive movement behavior (Russell et al. 1993). We divided the annual cycle into the same eight seasons used by McNeil et al. (2005), and used their classification system for seasonal environmental conditions most likely to affect movement. For each season, McNeil et al. (2005) identified one key environmental factor influencing caribou distribution, informed by local knowledge 
Table 2. Caribou movement zones and habitat types within each zone.

\begin{tabular}{|c|c|c|c|c|c|c|}
\hline \multirow{3}{*}{$\frac{\text { Zone }}{1}$} & \multirow{2}{*}{$\begin{array}{c}\text { Name } \\
\text { Coastal plain of ANWR }\end{array}$} & \multicolumn{2}{|c|}{ Habitat / topography by subzone } & \multirow{3}{*}{$\frac{\text { Community }}{\text { Kaktovik }}$} & \multirow{3}{*}{$\frac{\mathrm{Near}^{\dagger}}{1.1}$} & \multirow{2}{*}{$\frac{\mathrm{Far}^{\dagger}}{1.2,1.3,1.4}$} \\
\hline & & lowlands \& open tundra & $1.1,1.3,1.6$ & & & \\
\hline & & higher elevation tundra & $1.2,1.4,1.5$ & & & \\
\hline 2 & Brooks Range & mountain, alpine tundra & & & & \\
\hline 3 & Yukon North Slope & lowlands, open tundra & $3.1,3.2$ & & & \\
\hline & & mountain, alpine tundra & 3.3 & & & \\
\hline 4 & $\begin{array}{l}\text { Southern Brooks foothills \& } \\
\text { Chandalar Basin }\end{array}$ & mixed tundra / dwarf scrub & $4.1--4.4$ & Arctic Village & 4.1 & 4.2 \\
\hline 5 & Porcupine River Basin & $\begin{array}{l}\text { mixture of forest, scrub, wetlands } \\
\text { (Crow Flats, 5.2) }\end{array}$ & $5.1--5.7$ & Old Crow & 5.1 & $5.2--5.5$ \\
\hline 6 & Richardson Mountains & alpine tundra & $6.1--6.5$ & Aklavik & 6.1 & $6.2,6.3$ \\
\hline 7 & Yukon Flats & lowland forest \& lakes & $7.1--7.4$ & Venetie & 7.1 & 7.2 \\
\hline 8 & North Ogilvie Mountains & mountain, alpine tundra & $8.1,8.2$ & & & \\
\hline 9 & Dempster Highway & $\begin{array}{l}\text { Eagle Plains } \\
\text { tundra, scrub }\end{array}$ & $\begin{array}{l}9.1 \\
9.2,9.3\end{array}$ & Fort McPherson & $6.5,9.1$ & $9.2,9.3$ \\
\hline 10 & Peel River Plateau & mixed tundra / dwarf scrub & & & & \\
\hline 11 & Ogilvie Mountains & alpine tundra & & & & \\
\hline 12 & MacKenzie Mountains & alpine tundra & & & & \\
\hline 13 & West of ANWR & $\begin{array}{l}\text { coastal lowlands through foothill } \\
\text { tundra }\end{array}$ & & & & \\
\hline
\end{tabular}

${ }^{\dagger}$ Near areas are generally accessible for hunting on day trips from the community, while hunting in far areas requires at least one overnight stay on the land, from Kofinas and Braund (1998).

and expert scientific opinion. They used available climate data relevant to that seasonal factor's annual state to divide the years into two classes based on ranking of the years. For example, they defined early or late snowmelt as the key driver for spring migration, indicated by whether or not the snowpack measured on May 1 at Old Crow had declined by at least $30 \mathrm{~cm}$ from that measured on March 1. For fall migration, they determined whether snowfall was early or late, the key driver for that season, based on whether September snowfall at Old Crow was greater or less than $4.5 \mathrm{~cm}$ (McNeil et al. 2005). Table 3 summarizes the seasonal environmental drivers and classification of years by state.

\section{Converting point locations to movement records and assigning records to seasonal movement zones.}

We imported the 23,670 satellite collar locations from 1985-2003 into a geographic information system (GIS). On days for which we had multiple locations of the same animal, we sampled randomly to select a single daily location for each collared animal, which reduced the total number of observations to 19,509 . Prior to 1996 , the majority of the observations were spaced one or two days apart; starting in 1997, observations were generally reported at weekly intervals. We applied an ArcInfo script to connect consecutive point locations, assuming straight-line movement between observed locations (total of 19,419 line segments, mean length $21 \mathrm{~km}$ ), to create a continuous movement record for each animal. In many cases, the animal's movement record spanned multiple years. When the temporal gap between successive locations for an animal exceeded 30 days during winter months, or 10 days during other seasons, a new animal movement record was begun for that individual. The final dataset contained 88 separate animal movement records, with a mean distance traveled per record of $5732 \mathrm{~km}$, and a mean record duration of 562 days.

We overlaid the 88 movement records on Kofinas and Braund's (1998) 12 large-scale movement zones, and then examined each individual animal's movement record visually to ensure that no obvious location coding errors were present. Seasons were assigned to each line segment using the dates in Table 3. For several movement records, animals moved outside the perimeter of the 12 zones for as long as a year before returning. All of these outlying segments were located on the Alaska North Slope, west of the Canning River. We created a Zone 13 (Fig. 1) to accommodate this "out-of-range" movement, thereby bringing the count of subzones to 39 .

\section{Analyzing seasonal movements under differing environmental states}

We modeled movement probabilities for an individual collared animal as a Markov process driven by an externally imposed sequence of states of nature representing weather conditions and their ecological consequences. Let $q^{s}$ represent a row vector of length $k$ whose elements describe the number of animals observed during season $s$ in each of $k$ habitat zones defining the range of the herd. Let $P_{a}^{s}$ represent the transition matrix for movement of animals from season $s-1$ to season $s$ if state of nature $a^{s}$ is observed in season $s . P_{a}^{s}$ is a square matrix whose elements, $p_{a i j}^{s}$, represent the probability that an 
Table 3. Environmental condition classes and climate variables for eight seasons for the Porcupine Caribou Herd, based on data from McNeil et al. (2005).

\begin{tabular}{|c|c|c|c|c|}
\hline Model season $^{\dagger}$ & Dates & Measured environmental condition & Weather-driven state & Years $^{\dagger}$ true vs. false \\
\hline 1. Calving & $6 / 1-6 / 10$ & $\%$ snow cover within extent of calving & $\begin{array}{c}\text { Early snowmelt }<20 \% \\
\text { Late snowmelt }>20 \%\end{array}$ & $\begin{array}{c}\text { Early: 1985, 1990-91, } \\
\text { 1993-1996, 1998, 2002-03 }\end{array}$ \\
\hline 2. Postcalving & $6 / 11-6 / 30$ & $\begin{array}{c}21 \text { June NDVI - } 1 \text { June NDVI, within } \\
\text { extent of calving }\end{array}$ & $\begin{array}{l}\text { Fast green-up }>0.1 \\
\text { Slow green-up }<0.1\end{array}$ & $\begin{array}{c}\text { Fast: } 1988-89,1993-95,1997 \text {, } \\
1999-2001\end{array}$ \\
\hline 3. Early summer & $7 / 1-7 / 15$ & Rank of total June precipitation \& July & Few insects $<20$ & Few: 1986-87, 1991-92, \\
\hline 4. Mid - late summer & $7 / 6-8 / 7$ & mean max temperature, Old Crow & Many insects $>20$ & 1999-2001, 2003 \\
\hline 5. Fall migration & $8 / 8-10 / 7$ & Total September snowfall, Old Crow & Late snowfall $<4.5$-cm Early & Late: $1985-86,1989,1991$, \\
\hline 6. Rut / Late fall & $10 / 8-11 / 30$ & & snowfall $>4.5-\mathrm{cm}$ & $1997-99,2001-03$ \\
\hline 7. Winter & $12 / 1-3 / 31$ & March snow depth, Eagle Plains & $\begin{array}{c}\text { Shallow snow }<75-\mathrm{cm} \\
\text { Deep snow }>75-\mathrm{cm}\end{array}$ & $\begin{array}{c}\text { Shallow: } 1985-87,1994-97, \\
1999,2002\end{array}$ \\
\hline 8. Spring migration & $4 / 1-5 / 31$ & $\begin{array}{c}\text { (1 May snow depth) - (1 March snow } \\
\text { depth), Old Crow }\end{array}$ & $\begin{array}{l}\text { Early snowmelt }>30-\mathrm{cm} \\
\text { Late snowmelt }<30-\mathrm{cm}\end{array}$ & $\begin{array}{c}\text { Early: } 1988-91,1993-95,1998, \\
2003\end{array}$ \\
\hline
\end{tabular}

\footnotetext{
The eight seasons of a model year run from calving in calendar year through spring of the following calendar year, i.e., calving in model year 1985 represents June 1985, while spring migration represents April/May 1986.
}

NDVI $=$ Normalized Difference Vegetation Index

animal observed in zone $i$ in season $s-1$ will move to zone $j$ in season $s$ if state of nature $a^{s}$ occurs $\left({ }_{j} p_{a i j}^{s}=1\right)$. The expected number of animals in season $s$, given the observed distribution $q^{\mathrm{s}-1}$ is therefore,

$q^{s}=q^{s-1} P_{a}^{s}$

If state of nature $a^{s}$ occurs in season $s$ and state of nature $b^{s+1}$ occurs in season $s+1$, then the expected distribution of animals in season $s+1$ given the distribution in seasons $s-1$ would be:

$q^{\mathrm{s}+1}=q^{\mathrm{s}-1} P_{a}^{s} \mathrm{P}_{b}^{\mathrm{s}+1}$

The model allows for path-dependent movement. The expected distribution in a given season depends not only on the state of nature and starting distribution of animals, but also on the sequence of previous states of nature and animal locations. Although the path dependence theoretically could continue indefinitely, $\mathrm{PCH}$ distribution in practice is highly concentrated post calving (Russell and McNeil 2005), so the process essentially restarts each summer.

To derive the seasonal transition matrices, $P_{a}^{s}$ and $P_{b}^{s}$, we started by calculating from each caribou's movement record the proportion of days, $r_{i j}^{t}$, that the animal spent in zone $j$ in time period (year and season) $t$ if it had been observed in zone $i$ during the previous time period. We then divided all the observed individual proportions $r_{i j}^{t}$ into two pools for each season, depending on whether environmental state $a$ or state $b$ had occurred that season in that year. We estimated the contingent transition probabilities, $p_{a i j}^{s}$, finally, as the weighted average of the $r_{a i j}^{t}$, using as weights the total collared animal-days observed in zone $i$ in time period $t$-1. The appendix contains additional details of the calculation of the transition probabilities.

In most seasons, one or two years were underrepresented in the pooled dataset, in terms of collar numbers, but in no season were the probabilities computed using less than 40 collared individuals $($ mean $=65$, s.d. $=13.8)$. For each season there were at least five years of relatively equal collar numbers. The maximum proportional contribution from an individual year was typically 20 to $25 \%$, with only three cases exceeding $30 \%$ of the pooled data from an individual year. Location data for earlier years, when observations on individual animals were more frequent, may have recorded movement across the zones within a season more precisely for a given collared animal.

\section{Hypothesis tests using the transition probability tables}

Using the 16 calculated transition matrices, i.e., two environmental conditions for each of 8 seasons, we constructed two statistical tests of our hypotheses about caribou movement. Our first hypothesis, path dependence, was that the zone in which an animal began one season significantly affected the probability that it would end in a given zone the following season. Our second hypothesis, climate variation, was that different climate states in certain seasons also led to significantly different probabilities of moving to a particular destination zone from a given origin zone.

To test for path dependence, we tested whether the transition probability, $p_{s a i j}$, differed from the mean $p_{\text {saij }}$ for destination $j$, using a $t$ test with the number of animal-seasons observed in the cell as the degrees of freedom. We rounded the cell animalseasons up on the basis that if 2.1 animal-seasons were observed, it implied that there had been observations on at least three animals. We considered this a conservative interpretation because there are arguably as many degrees of freedom as there are animals, or possibly even collar points, in each cell. To test for effects of climate variation, we tested the null hypothesis that the probability of moving between any two zones $i$ and $j$ was the same for different states of the environmental condition, that is, $p_{s b i j}=p_{s a i j}$, for all seasons $s$ and associated environmental states $a$ and $b$. We performed 
two tests: (1) difference of means ( $t$ test), with the test variance based on the number of animal-seasons observed in the origin zone, and (2) contingency table of actual vs. expected collarseasons for multiple destination zones from a given origin (chisquared). We examined the cases of significant difference to understand whether a path-dependent pattern of movement could explain the differences in overall distribution that McNeil et al. (2005) attributed to environmental conditions.

\section{Simulating seasonal path-dependent herd-scale movements over a decadal time frame}

We built a dynamic stochastic simulation model of seasonal caribou distribution driven by an externally imposed sequence of ecological conditions. The model simulates movements of a set of hypothetical individual animals among the 13 zones in a Markov chain using transition matrices calculated from movement records. The model has the option of a binary random draw for each season's environmental state or a preprogrammed set of seasonal states, i.e., to simulate a historical period for which the seasonal states of nature were known. Given the environmental state, each animal moves to a destination zone according to its own independent random draw from the distribution specified by the season-statespecific transition matrix. Once the model assigns animals to their respective zones, it randomly distributes animals into the 39 smaller harvest subzones using a distribution built from the seasonal utilization density grids calculated in McNeil et al. (2005) specific to the season and prevailing ecological driver. An appendix contains a detailed description of the model, the simulation protocol, and error checking.

We ran 1000 Monte Carlo simulations of the model spanning a 19-year simulation horizon (June 1985-May 2003). For each run, the caribou herd was represented by 28 hypothetical animals, as described in the appendix. We initialized the model with the observed calving distribution in June 1985 (Griffith et al. 2002), and then simulated sequentially across eight seasons per year using the observed historical progression of ecological drivers. For each of the 39 hunting subzones for each year-season, we computed the 5th, 50th, and 95th percentiles among runs for the simulated number of caribou. The sum of all animals across the 1000 runs produced a dynamic simulation of the distribution of 28,000 animals. Because the transition tables were derived from means of observed animals, adding up the animals in each year-seasonsubzone across the Monte Carlo runs bootstraps the simulated herd distribution. The Porcupine Caribou Herd during this period averaged around 140,000 animals, so multiplying by 5 provides an estimate of the actual expected number of animals by subzone. Figure 2 illustrates how the model simulates pathdependent movement for an example year. The figure shows simulated caribou density during calving for two years with identical environmental conditions, but with somewhat different distributions during the previous season, i.e., spring migration.
Fig. 2. Illustration of model simulations for two adjacent seasons in 1990 and 1994. Snowmelt was early in both years; however, in 1994, more caribou started far south in zone 8 during spring migration, resulting in higher calving densities in zones 3 and 5 to the east of the coastal plain.

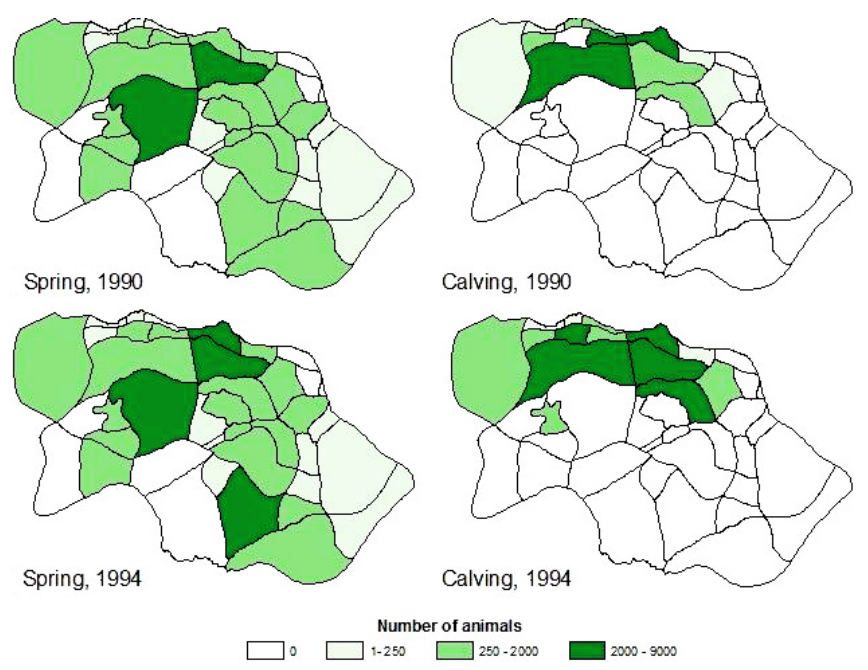

Although the term 'validation' is widely used with models, we agree with Oreskes et al. (1994) that the word 'validate' from the Latin validus (= true) implies inaccurately that a simulation model is a true and complete representation of reality. We therefore use the term 'evaluate,' which implies testing a model against certain specified standards of performance. We evaluated the model by testing its simulation output against two independent datasets: caribou distribution maps from aerial reconnaissance, and data on harvest success from three user communities.

\section{Hypothesis tests based on simulated herd movements}

Presence/absence comparisons with seasonal caribou habitat use maps, 1985-1990

We digitized distribution maps that Russell et al. (1993) derived from aerial over-flights conducted by the Canadian Wildlife Service (CWS), U.S. Fish and Wildlife Service (USFWS), and the Alaska Department of Fish and Game (ADFG) from 1970-1990. Data from these surveys are independent of the satellite collar data used for model development. Russell et al. (1993) provided distribution maps that coincide with model simulations in 23 seasons between June 1985 and June 1990. Using ArcGIS 9.1, we spatially joined these data to calculate the percentage of simulated animals contained within the observed $\mathrm{PCH}$ distribution by season and year. We also calculated the percentage of area within the observed $\mathrm{PCH}$ distribution that the model predicted 
would be occupied using different thresholds $(0 \%, 1 \%$, and 5\%). Distribution maps in Russell et al. (1993) represent the boundaries within which caribou were sighted in the particular season and year. Animals could have been present outside the distribution map but not observed. Consequently, the evaluation with this dataset focuses primarily on false negative errors: instances for which the model predicted caribou absence in a subzone in which agency biologists observed caribou present.

Correlation of caribou abundance with community harvests For different periods between 1987 and 1997, seasonal harvest data were collected for the communities of Aklavik, Old Crow, and Fort McPherson by the Yukon Native Harvest Program (PCTC 1994). We used these data to estimate partial correlations between the simulated number of animals present in a zone or subzone for a given year-season, and the reported harvest by community in that zone or subzone during that same year-season. Kofinas et al. (2002) and Kofinas and Braund (1998) provided the method, based on knowledge from local informants, for assigning the individual reported harvest records from the geography reported to the 38 community hunting subzones, excluding zone 13 , for which no harvest was recorded.

Based on local knowledge, hunters in the harvesting communities of Old Crow, Fort McPherson, Aklavik, Arctic Village, and Kaktovik had classified each relevant subzone as "near" or "far" to their community (Kofinas and Braund 1998, Berman and Kofinas 2004). We summarized the reported harvest by zone and subzone by year, season, and community. We then calculated simple correlations between the simulation output and reported harvest in "near" subzones, assuming that animals might be present somewhere in the subzone, but not necessarily accessible to hunters. We set an alpha prior significance value of 0.05 . The harvest data set covered the period from 1987-1997, but did not include all years for each community, nor all seasons within any given year. We included only the main 'near' harvest areas for Aklavik (76 data seasons from 1987-1997), Old Crow (48 data seasons from 1988-1994), and Fort McPherson (20 data seasons from three years 1995-1997) because if animals are present near the community, hunters might get all they need without ever looking farther afield.

\section{RESULTS}

\section{Statistical tests for path-dependence and effects of seasonal climate outcomes}

\section{Path-dependence: was destination probability independent} of origin zone?

The null hypothesis for our test of path-dependence is that the destination probability for a specific origin zone, given the season and environmental driver, was the same as the mean destination probability for all origin zones for that season and driver. The results of this test indicated that significant differences (two-tailed $p<0.025$ ) do indeed appear in every one of the eight seasons, and for both categories of the driving condition in each season. With 775 nonzero cells in the transition matrices (out of a total of $13 \times 13$ origin-destination pairs $\times 8$ seasons $\times 2$ binary conditions per season $=2704$ potential transitions), one would expect that 39 would randomly exceed the two-tailed five percent significance threshold difference from the row mean if the destination zone were independent of the origin zone. In fact, 88 pairs (11.4\% or 2.3 times expected) were significantly different from the row mean. Seasonally, the fewest significant differences were found during the rut, 6 origin-destination pairs, and the most, 20 , during spring migration. In spring, caribou movement is most strongly directional northward toward the calving grounds (Eastland 1991, Griffith et al. 2002). All significant cases of path-dependence during spring migration were for origin-destination pairs of caribou moving northward, e.g., from the Richardson Mountains northward to the Yukon North Slope, or the Yukon flats northward toward the Brooks Range. We inferred from this analysis that the distribution of Porcupine Caribou in a given season did depend, at least in part, on their distribution the previous season.

\section{Seasonal weather effects: did environmental drivers influence the movement probabilities?}

The null hypothesis for this test is that the origin-destination probability in a given season was the same under both environmental states. Although McNeil et al. (2005) showed that the mean herd distribution differed by environmental condition for certain subzones and seasons, we sought here to test whether records of season-to-season movement of individual caribou also exhibited those differences. Our results (Table 4) rejected the null hypothesis $(\mathrm{p}<0.05)$ in four of the eight seasons using both the test for difference of means $(t$ test) and the test of actual vs. expected cross-tabulation (chisquared).

In calving season, early June, late snowmelt on the calving grounds significantly increased the probability that caribou in the Porcupine Basin (zone 5) and on the Yukon North Slope (zone 3) in early April moved to the Brooks Range (zone 2) in early June; early snowmelt was associated with movement to the coastal plain (zone 1) for calving. Late snowmelt also increased the probability that caribou that were further from the coastal plain in April, e.g., in the Richardsons or Ogilvies (zones 6 and 11), calved in Canada on the Yukon North Slope (zone 3) and in the Porcupine Basin (zone 5), respectively. In general, the calving movement record results were consistent with the findings of Griffith et al. (2002) that in years with early snowmelt, caribou tended to calve on the Alaska Arctic coastal plain where calf survival was typically higher than in the foothills, where calving took place during late snowmelt years. High insect levels during early summer (July 1-15) reduced the probability that animals that were on the Yukon 
Table 4. Seasons, origins, and destinations for which environmental conditions significantly affected caribou movements: actual vs. expected probabilities of moving given previous season origin, with test probabilities for difference of means ( $\mathrm{t}$ ) and actual vs. expected for destination pairs (Chi-sq).

\begin{tabular}{|c|c|c|c|c|c|c|c|c|}
\hline $\begin{array}{l}\text { Season at } \\
\text { destination }\end{array}$ & $\begin{array}{c}\text { Origin } \\
\text { zone }\end{array}$ & Destination zone & States (A vs. B) & State A prob. & $\begin{array}{l}\text { State B } \\
\text { prob. }\end{array}$ & $\begin{array}{c}\text { Expected } \\
\text { prob. }\end{array}$ & $\mathrm{t}$ & Chi-sq \\
\hline \multirow[t]{6}{*}{ Calving } & 5 & 1 & early vs. late snowmelt & 0.591 & 0.110 & 0.236 & 0.032 & 0.036 \\
\hline & & 2 & & 0.061 & 0.394 & 0.306 & 0.040 & \\
\hline & 3 & 2 & & 0.100 & 0.494 & 0.367 & 0.004 & 0.020 \\
\hline & & 3 & & 0.366 & 0.170 & 0.234 & 0.234 & \\
\hline & 6 & 3 & & 0.049 & 0.482 & 0.410 & 0.046 & -- \\
\hline & 11 & 5 & & 0.034 & 0.668 & 0.557 & 0.016 & -- \\
\hline \multirow[t]{2}{*}{ Summer } & 3 & 2 & low vs. high insects & 0.450 & 0.014 & 0.346 & $<0.001$ & 0.012 \\
\hline & & 3 & & 0.055 & 0.350 & 0.125 & 0.124 & \\
\hline \multirow[t]{2}{*}{ Rut } & 5 & 5 & early vs. late snowfall & 0.072 & 0.335 & 0.190 & 0.022 & 0.010 \\
\hline & & 6 & & 0.222 & 0.049 & 0.144 & 0.067 & \\
\hline \multirow[t]{2}{*}{ Winter } & 6 & 6 & deep vs. shallow snow & 0.677 & 0.000 & 0.062 & $<0.001$ & 0.032 \\
\hline & & 8 & & 0.001 & 0.231 & 0.021 & 0.5 & \\
\hline
\end{tabular}

North Slope (zone 3) in late June would move into the Brooks Range (zone 2). During the rut and late fall (Oct 8-Nov 30), early snowfall increased the probability that caribou that had been in the Porcupine Basin (zone 5) in August and September would move to another zone, i.e., it reduced the probability that they would remain in zone 5. During winter, deep snow increased the probability that animals located in the Richardson Mountains (zone 6) would stay in that zone.

Although significant differences appeared in relatively few cases, one should keep in mind the limited power of the tests. The relatively small number of collar observations for origindestination pairs under a given environmental condition magnifies the size of differences in probabilities needed to pass the significance threshold. For the $t$ tests, an expected probability, averaged across states, of 1.5 times its standard error implies that the actual probability of a given origindestination move would have to be 3 times greater in one environmental state than in the other, quite a large difference, for the difference of means to have a probability $<0.05$. There were 55 total origin-destination pairs with an expected probability of at least 1.5 times the standard error, of which 8 $(15 \%)$ showed significant differences with the $t$ test. All the destination pairs showing significant differences of average from expected probabilities in the chi-squared test came from origin zones with at least 18 collar-seasons of observations for the given season. Caribou were concentrated in a few zones in most seasons, so that there were only 25 cases of origin zones with at least 18 observed collar-seasons (average 3.1 zones per season). Of these, five (20\%) showed significant differences in the chi-squared test.

Testing simulation results against empirical observations Our evaluation of the model simulations focused first on the issue of erroneous predictions. In other words, we examined whether the model predicted that caribou were absent in subzone-season-year combinations, when we know empirically that caribou were in fact present.

\section{Comparing presencelabsence against seasonal distribution maps}

From the seasonal distribution maps in Russell et al. (1993), we evaluated the percentage area in each seasonal distribution polygon in which the model predicts no caribou at the 95th percentile. Overall for the 23 seasons available, only $2 \%$ of the distribution area lay in subzones in which the model predicted no caribou (Table 5). The model most consistently predicted the distribution of animals accurately during calving, when caribou are highly concentrated (Table 5), and least consistently predicted correct locations during spring migration, when caribou are moving rapidly and are highly dispersed. Because the CWS data were derived from airsupported visual surveys, they could underestimate the extent of herd distribution in any given observation period, especially if herds dispersed into smaller groups. A useful comparison statistic is the average amount of observed area in which the model predicts very few animals. On average, $16 \%$ of the observed area of caribou distributions overlapped subzones that contained $5 \%$ of the animals predicted by the model (Table 5). Only $2 \%$ of the observed caribou distribution area overlapped with subzones in which the model predicted no animals present. These statistics suggest that the model rarely placed animals in subzones in which few caribou were observed. We concluded from the results of the GIS overlay analysis that our model is effective in simulating caribou distributions by subzone on a seasonal basis.

\section{Correlating caribou abundance with availability to and harvest by communities}

The second set of tests examines true positives, whether the model also predicts caribou presence where we know empirically that caribou were present: because hunters 
Table 5. Mean percent of area of caribou distribution observed by Russell et al. (1992) in subzones with few or no predicted animals.

\begin{tabular}{|c|c|c|c|c|}
\hline Season & $\begin{array}{c}\text { Number of years with valid } \\
\text { observations }\end{array}$ & $\begin{array}{l}\% \text { area caribou observed w. no } \\
\text { predicted animals }\end{array}$ & $\begin{array}{c}\% \text { area caribou observed } \mathrm{w} .< \\
1 \% \text { of predicted animals }\end{array}$ & $\begin{array}{c}\% \text { area caribou observed w. }< \\
5 \% \text { of predicted animals }\end{array}$ \\
\hline Calving & 6 & $1 \%$ & $3 \%$ & $7 \%$ \\
\hline Postcalving & 1 & $0 \%$ & $0 \%$ & $6 \%$ \\
\hline Summer 1 & 1 & $0 \%$ & $4 \%$ & $16 \%$ \\
\hline Summer 2 & 1 & $0 \%$ & $1 \%$ & $6 \%$ \\
\hline Early fall & 5 & $0 \%$ & $3 \%$ & $12 \%$ \\
\hline Rut & 3 & $0 \%$ & $1 \%$ & $12 \%$ \\
\hline Winter & 3 & $1 \%$ & $7 \%$ & $30 \%$ \\
\hline Spring & 3 & $13 \%$ & $21 \%$ & $40 \%$ \\
\hline TOTAL & 23 & $2 \%$ & $6 \%$ & $16 \%$ \\
\hline
\end{tabular}

reported harvesting them. All the correlations are positive, and most are significant (Table 6). Cases in which the model results were not significant included the Old Crow borderlands (subzone 5.4, $\mathrm{p}=0.16$ ), and the Fort McPherson cases. This subzone runs across the border, so it is possible that animals were present in the subzone but on the U.S. side of the border where Old Crow hunters cannot legally harvest them, or that hunters prefer to hunt upstream and return loaded to Old Crow with the assistance of the downstream current (Berman and Kofinas 2004). Harvest data exist for only 20 seasons for Fort McPherson, where the Dempster Highway provides access for hunters. Because of easier access and limited data, we also computed categorical correlations for this community, i.e., presence/absence, using the binary model prediction of $1=$ animals present, and $0=$ animals absent. All binary correlations were significant. These tests suggest that the model simulations of caribou availability to user communities are consistent with the available harvest data.

\section{DISCUSSION}

\section{Statistical tests and caribou movement decisions}

The statistical tests on the origin-destination matrices supported our hypotheses about seasonal caribou movements, namely that caribou distribution and availability to communities depended both on seasonal climate outcomes and the animals' locations in the previous season. Origindestination probabilities differed significantly across environmental states in only eight cases, and ecological drivers had no significant effects in half of the seasons, i.e., postcalving, midsummer, fall migration, and spring migration. Nevertheless, three factors mitigate against concluding that environmental drivers played only a minor role overall in seasonal herd distribution. First, the finding that caribou movements were path-dependent implies that if animals were frequently present in zones where weather conditions did affect their movement decisions, the distribution the following season, and possibly in subsequent seasons, would bear some 'imprint' of that decision. In fact, an average of $19 \%$ (maximum 37\%) of the collar observations came from the relevant zones for each of the eight seasons in which seasonal weather conditions significantly affected movement. Second, McNeil et al. (2005) found that ecological drivers were associated with significant differences in overall mean herd distribution near the communities of Kaktovik, Arctic Village, Venetie, Old Crow, Aklavik, and Fort McPherson. Third, interannual variation in seasonal caribou harvest in these communities was significantly associated with interannual availability of caribou predicted from model simulations driven by observed seasonal weather conditions.

Although the results provided general evidence of pathdependent movement driven by seasonal climate variation, one should exercise caution in applying them to different scales from those used in the analysis. The coarse spatial scale of the movement zones, on the order of tens of thousands of square $\mathrm{km}$, limited the study's ability to observe differences in movement patterns. The uneven size of zones, combined with the uneven time step, also reduced the precision of modelsimulated movement, especially during seasons of rapid displacement. For example, the transition table for modeled movement would record a probability that animals were present in a zone and season even if they had been only moved through a small portion of the zone. We chose the scales for analysis because they had been justified as relevant to $\mathrm{PCH}$ movement in previous research (Kofinas and Braund 1998, McNeil et al. 2005). Using smaller spatial scales would have provided more power for statistical tests of path and weatherdependent movement, but possibly greater unexplained, random, movement variation and difficulty with validation. Shorter time scales would be more difficult to analyze, but might allow for tests of timing of movement as well as transition across space.

\section{Applying the modeling framework to other herds and species}

The approach we have used can easily be adapted to model the movement of other caribou herds. Person et al. (2007), for example, summarized the seasonal movements of the 
Table 6. Partial correlation between simulated abundance of animals in a subzone during a given season and reported harvest by community for that same subzone and season.

\begin{tabular}{|c|c|c|c|c|c|c|}
\hline Community & data years & data seasons & main hunting areas & harvest records & $\begin{array}{l}\mathrm{r}^{2} \text { correlation with } \\
\text { model prediction }\end{array}$ & $\mathrm{p}$ value \\
\hline \multirow[t]{3}{*}{ Aklavik } & 1987-1997 & 76 & 3.1: Yukon N. Slope E. & 211 & 0.426 & $<0.001$ \\
\hline & & & 6.1: Richardson Mts N. & 349 & 0.462 & $<0.001$ \\
\hline & & & 6.3: MacKenzie Delta W. & 195 & 0.455 & $<0.001$ \\
\hline \multirow[t]{4}{*}{ Old Crow } & 1988-1994 & 48 & 5: Porcupine R. & 321 & 0.503 & $<0.001$ \\
\hline & & & 5.2: Crow Flats & 79 & 0.507 & $<0.001$ \\
\hline & & & 5.4: Borderlands & 67 & 0.202 & 0.164 \\
\hline & & & 5.6: Old Crow South & 147 & 0.396 & 0.005 \\
\hline \multirow[t]{2}{*}{ Ft. McPherson } & 1995-1997 & 20 & 9: Dempster Hwy & 331 & 0.363 & 0.109 \\
\hline & & & 9.1: Eagle Plains & 286 & 0.362 & 0.107 \\
\hline
\end{tabular}

Teshekpuk Caribou Herd in northern Alaska, and McNeil et al. (2005) applied the same framework of eight caribou seasons with binary ecological drivers to the Bathurst Herd in Canada's Northwest Territories. Requirements to model sequential seasonal movement of these and other herds include satellite collar location data, as well as hypotheses about the ecological factors thought to influence caribou movement in the different seasons.

Modeling dynamic availability to hunters using our approach would require that biologists and/or managers collaborate with local hunters to delineate distinct zones that capture seasonal distribution patterns of their herd that reflect both differences between seasons and interannual variability in distribution for the same season. If information is known about potential locations of industrial development, these areas could inform the selection of zone boundaries (McNeil et al. 2005). Using the model to simulate caribou availability to communities would also require knowledge of local seasonal hunting areas and practices. We believe that our two-level hierarchical delineation, i.e., large-scale movement zones and smaller hunting subzones, provides the right level of spatial resolution given the available satellite data, current understanding of caribou movement ecology, and the goal of understanding the availability of caribou to hunters in specific communities.

Might the modeling framework be applied to other migratory species? Mueller et al. (2008) suggested that Mongolian gazelles do not exhibit regular annual fidelity to a calving ground as caribou do, and that their environment is more variable from year to year. A satellite-collaring project is currently underway, and once more data are available, the utility of this modeling framework could be tested for a species that appears more nomadic than migratory (Mueller and Fagan 2008, Olson et al. 2010).

\section{A note on model evaluation: false positives and true negatives}

The four sets of evaluation tests all point to the conclusion that our origin-destination modeling approach does provide an accurate representation of caribou movement and distribution.
However, we agree with Oreskes et al. (1994) that they do not add up to 'validation.' Each test has its own limitations. Without full knowledge of the entire herd's distribution in every season, we cannot claim to be 'validating' the model because the possibility always exists that additional observations might invalidate the model.

The satellite collar data and the distribution maps from aerial over-flights can confirm caribou presence, but they do not necessarily tell us about caribou absence from a zone. In the case of the satellite collars, sample sizes are too small to infer that no caribou were present if no collars were observed for a given zone-season. Likewise, we cannot be sure that lack of recorded caribou in a given location during an aerial survey was not simply a lack of observational effort in that area. Community-based monitoring, such as the U.S.-Canada Arctic Borderlands Ecological Knowledge Coop, provides an important opportunity to test hypotheses, evaluate model output, and synthesize local and science-based knowledge. The Coop has assembled 10 years of observations on caribou availability by local residents in various seasons (Kofinas et al. 2002).

\section{CONCLUSION}

We modeled caribou movement with the objective of capturing social as well as ecological dynamics of a North American caribou herd. We tested hypotheses of animal movement and their implications by (1) estimating seasonal movement probabilities of Porcupine Caribou relative to key climate-related environmental conditions, (2) testing for statistically significant differences in these probabilities, (3) simulating retrospectively the sequential seasonal movements and the resulting distribution of the $\mathrm{PCH}$ from 1985-2000, and (4) testing correlations between reported seasonal harvests from communities and simulated seasonal herd distributions. As a further test of the credibility of the simulated seasonal distributions, we evaluated the results of the model against independent observations of Porcupine Caribou distribution.

Our findings suggest several future research developments. First, although we simulated the model with retrospective 
climatologies, one could use it prospectively. Because the external forcing variables in our simulation model are directly related to seasonal weather variation, one could use the model to explore how future climate change may affect caribou movement and availability to local community hunters at different times of year. Doing so would provide an objective method to quantify the future risks of caribou scarcity for different communities in response to projected climate scenarios. Prospective simulations might also provide highly relevant information for environmental assessments, including analyses of how climate variation or climate change might affect potential seasonal caribou movement near development projects. Second, we suspect that certain communities may be more vulnerable to caribou availability than others, but this has been difficult to quantify in a testable hypothesis. We plan to use our model to analyze how the location of communities within the range of the herd affects their risk of caribou scarcity, and how different climate scenarios mitigate or increase this risk. Third, because caribou energy expenditure depends heavily on their movements, particularly in deep winter snows and during spring migration, and because energy expenditure could affect body condition and reproductive success, we plan to integrate this movement model with models of energetics and population dynamics.

Responses to this article can be read online at: http://www.ecologyandsociety.org/issues/responses. $\mathrm{php} / 5376$

\section{Acknowledgments:}

Authors of this paper gratefully acknowledge the input and support of community residents from Old Crow, Fort McPherson, Aklavik, and Arctic Village who helped define the caribou movement zones and contributed other local knowledge. We thank Joe Tetlichi for his input in developing the model, and Todd Fuller for his valuable critical reviews of earlier drafts of the manuscript. We are grateful to Dorothy Cooley of the Yukon Government for data collection and analysis of the Porcupine Caribou satellite collar locations. This work received financial support from the U.S. National Science Foundation (OPP 0531200, DEB 0743385, OPP 9521459, OPP 9909156).

\section{LITERATURE CITED}

Arthur, S. M., K. R. Whitten, F. J. Mauer, and D. Cooley. 2003. Modeling the decline of the Porcupine Caribou Herd, 1989-1998: the importance of survival vs. recruitment. Rangifer Special Issue 14:123-130.

Berman, M., and G. Kofinas. 2004. Hunting for models: grounded and rational choice approaches to analyzing climate effects on subsistence hunting in an Arctic community. Ecological Economics 49:31-46. http://dx.doi.org/10.1016/j. ecolecon.2003.12.005

Berman, M., C. Nicolson, G. Kofinas, J. Tetlichi, and S. Martin. 2004. Adaptation and sustainability in a small Arctic community: results of an agent-based simulation model. Arctic 57:401-414. [online] URL: http://pubs.aina.ucalgary.ca/ arctic/arctic57-4-401.pdf

Burch, E. S., Jr. 1998. The Inupiaq Eskimo nations of Northwest Alaska. University of Alaska Press, Fairbanks, Alaska, USA.

Burch, E. S., Jr. 2012. Caribou herds of Northwest Alaska, 1850-2000. University of Alaska Press, Fairbanks, Alaska, USA.

Chance, N. A. 1966. The Eskimo of North Alaska. Holt, Rinehart and Winston, New York, New York, USA.

Chapin, F. S., III, G. P. Kofinas, and C. Folke, editors. 2009. Principles of ecosystem stewardship: resilience-based natural resource management in a changing world. Springer-Verlag, New York, New York, USA.

Craighead, J. J., G. Atwell, and B. W. O'Gara. 1972. Elk migration in and near Yellowstone National Park. Wildlife Society Monograph 29. Allen Press, Lawrence, Kansas, USA.

Dingle, H. 1996. Migration: the biology of life on the move. Oxford University Press, New York, New York, USA.

Dingle, H., and V. A. Drake. 2007. What is migration? Bioscience 57:113-121.

Eastland, W. G. 1991. Influence of weather on movements and migration of caribou. Dissertation. University of Alaska Fairbanks, Fairbanks, Alaska, USA.

Estes, R. D. 1991. The behavior guide to African mammals: including hoofed mammals, carnivores, primates. University of California Press, Berkeley, California, USA.

Fancy, S. G., L. F. Pank, K. R. Whitten, and W. L. Regelin. 1989. Seasonal movements of caribou in Arctic Alaska as determined by satellite. Canadian Journal of Zoology 67:644-650. http://dx.doi.org/10.1139/z89-093

Fienup-Riordan, A. 1986. When our bad season comes: a cultural account of subsistence harvesting and harvest disruption on the Yukon Delta. Alaska Anthropological Association, Anchorage, Alaska, USA.

Folke, C. 2006. Resilience: The emergence of a perspective for social-ecological systems analyses. Global Environmental Change 16:253-267. http://dx.doi.org/10.1016/j.

gloenvcha.2006.04.002 
Forbes, B.C., F. Stammler, T. Kumpula, N. Meschtyb, A. Pajunen, and E. Kaarlejärvi. 2009. High resilience in the Yamal-Nenets social-ecological system, West Siberian Arctic, Russia. Proceedings of the National Academy of Sciences 106:22041-22048. http://dx.doi.org/10.1073/ pnas.0908286106

Griffith, B., D. C. Douglas, N. E. Walsh, D. D. Young, T. R. McCabe, D. E. Russell, R. G. White, R. D. Cameron, and K. R. Whitten. 2002. The Porcupine Caribou Herd. Pages 8-37 in D. C. Douglas, P. E. Reynolds, and E. B. Rhode, editors. Arctic refuge coastal plain terrestrial wildlife research summaries. U. S. Geological Survey, Biological Resources Division, Reston, Virginia, USA. [online] URL: http://alaska. usgs.gov/BSR-2002/index.html

Hanley, T. A., and D. E. Russell. 2000. Ecological role of hunting in population dynamics and its implications for comanagement of the Porcupine Caribou Herd. Rangifer Special Issue 12:71-78.

Harris, G., S. Thirgood, J. G. C. Hopcraft, J. P. G. M. Cromsight, and J. Berger. 2009. Global decline in aggregated migrations of large terrestrial mammals. Endangered Species Research 7:55-76 http://dx.doi.org/10.3354/esr00173

Hayes, R. D., and D. E. Russell. 2000. Predation rate by wolves on the Porcupine Caribou Herd. Rangifer Special Issue 12:51-58.

Ito, T.Y., N. Miura, B. Lhagvasuren, D. Enkhbileg, S. Takatsuki, A. Tsunekawa, and Z. Jiang. 2006. Satellite tracking of Mongolian gazelle (Procapra gutturosa) and habitat shifts in their seasonal ranges. Journal of Zoology (London) 269:291-298.

Jernsletten, J.-L. L., and K. Klokov. 2002. Sustainable reindeer husbandry: report to the Arctic Council 2000-2002. Centre for Saami Studies, University of Tromsø, Troms $\varnothing$, Norway. [online] URL: http://www.reindeer-husbandry.uit. no/online/Final Report/final report.pdf

Kofinas, G., Aklavik, Arctic Village, Old Crow, and Fort McPherson. 2002. Community contributions to ecological monitoring: knowledge co-production in the U.S.-Canada Arctic borderlands. Pages 54-91 in I. Krupnik and D. Jolly, editors. The Earth is faster now: indigenous observations of Arctic environmental change. ARCUS, Fairbanks, Alaska, USA. [online] URL: http://www.taiga.net/coop/community/ earthfaster_kofinas.pdf

Kofinas, G. P., and S. Braund. 1998. Local caribou availability; a draft report from community involvement phase 2 of the NSF sustainability community project. Institute of Social and Economic Research, Anchorage, Alaska, USA.[online] URL: http://www.taiga.net/sustain/lib/reports/ availability.pdf
Kruse, J. A., R. G. White, H. E. Epstein, B. Archie, M. Berman, S. R. Braund, F. S. Chapin, III, J. Charlie, Sr., C. J. Daniel, J. Eamer, N. Flanders, B. Griffith, S. Haley, L. Huskey, B. Joseph, D. R. Klein, G. P. Kofinas, S. M. Martin, S. M. Murphy, W. Nebesky, C. Nicolson, D. E. Russell, J. Tetlichi, A. Tussing, M. D. Walker, and O. R. Young. 2004. Modeling sustainability of Arctic communities: an interdisciplinary collaboration of researchers and local knowledge holders. Ecosystems 7:815-828. http://dx.doi.org/10.1007/s10021-004-0008$\underline{\mathrm{Z}}$

McCabe, J. T. 2004. Cattle bring us to our enemies: Turkana ecology, politics, and raiding in a disequilibrium system. University of Michigan Press, Ann Arbor, Michigan, USA.

McNeil, P., D. E. Russell, D. B Griffith, A. Gunn, and G. P. Kofinas. 2005. Where the wild things are: seasonal variation in caribou distribution in relation to climate change. Rangifer Special Issue 16: 51-63. http://dx.doi.org/10.7557/2.25.4.1770

Mueller, T., and W. F. Fagan. 2008. Search and navigation in dynamic environments - from individual behaviors to population distributions. Oikos 117, 654-664. http://dx.doi. org/10.1111/j.0030-1299.2008.16291.x

Mueller, T., K. A. Olson, T. K. Fuller, G. B. Schaller, M. G. Murray, and P. Leimgruber. 2008. In search of forage: predicting dynamic habitats of Mongolian gazelles using satellite-based estimates of vegetation productivity. Journal of Applied Ecology 45:649-658. http://dx.doi.org/10.1111/ j.1365-2664.2007.01371.x

Olson, K. A., T. K. Fuller, T. Mueller, M. G. Murray, C. Nicolson, D. Odonkhuu, S. Bolortsetseg, and G. B. Schaller. 2010. Annual movements of Mongolian gazelles: nomads in the Eastern Steppe. Journal of Arid Environments 74:1435-1442. http://dx.doi.org/10.1016/j.jaridenv.2010.05.022

Oreskes, N., K. Shrader-Frechette, and K. Belitz. 1994. Verification, validation, and confirmation of numerical models in the earth sciences. Science 263:641-646. http://dx. doi.org/10.1126/science.263.5147.641

Person, B. T., A. K. Prichard, G. M. Carroll, D. A. Yokel, R. S. Suydam, and J. C. George. 2007. Distribution and movements of the Teshekpuk Caribou Herd, 1990-2005: prior to oil and gas development. Arctic 60:238-250. [online] URL: http://pubs.aina.ucalgary.ca/arctic/Arctic60-3-238.pdf

Porcupine Caribou Technical Committee (PCTC). 1994. Harvest reporting review, 1994, submitted to International Porcupine Caribou Board. Porcupine Caribou Management Board, Whitehorse, Yukon Territory, Canada.

Russell, D. E., A. M. Martell, and W. A. C. Nixon. 1993. The range ecology of the Porcupine Caribou Herd in Canada. Rangifer Special Issue 6:168. http://dx.doi.org/10.7557/2.13.5.1057 
Russell, D. E., and P. McNeil. 2005. Summer ecology of the Porcupine Caribou Herd. Porcupine Caribou Management Board, Environment Canada, Canadian Wildlife Service, Whitehorse, Yukon Territory, Canada. [online] URL: http:// www.taiga.net/pcmb/summer ecology/PCHSummerEcology3. pdf

Russell, D. E., K. R. Whitten, R. Farnell, and D. v. d. Wetering. 1992. Movements and distribution of the Porcupine Caribou Herd, 1970-1990. Technical Report Series No. 139, Canadian Wildlife Service, Pacific and Yukon Region, Delta, British Columbia, Canada.

Walsh, N. E., S. G. Fancy, T. R. McCabe, and L. F. Pank. 1992. Habitat use by the Porcupine Caribou Herd during predicted insect harassment. Journal of Wildlife Management 56:465-473. http://dx.doi.org/10.2307/3808860 


\section{Appendix 1. Simulating path-dependant seasonal herd movements}

The movement model assumes a Markov process driven by an externally imposed sequence of states of nature. Let $q^{s}$ represent a row vector of length $k$ whose elements describe the number of animals observed during season $s$ in each of $k$ habitat zones defining the range of the herd. Let $P_{a}^{s}$ represent the transition matrix for movement of animals from season $s-1$ to season $s$ if state of nature $a^{s}$ is observed in season $s . P_{a}^{s}$ is a square matrix whose elements, $p_{a i j}^{s}$, represent the probability that an animal observed in zone $i$ in season $s$-1 will move to zone $j$ in season $s$ if state of nature $a^{s}$ occurs $\left(\Sigma_{j} p_{a i j}^{s}=1\right)$. The expected number of animals in season $s$, given the observed distribution $q^{s}$ and state of nature $a^{s}$ is

$$
q^{s}=q^{s-1} P_{a}^{s}
$$

\section{Deriving the transition probabilities}

To derive the seasonal transition matrices, $P^{s}{ }_{a}$ and $P^{s}{ }_{b}$, we started by calculating from each caribou's movement record the proportion of time, $r^{\text {st }}{ }_{a i}$ that the animal spent in zone $j$ in season $s$ of year $t$ and if it had been observed in zone $i$ during the previous period $(t, s-1)$ for all years and seasons for which the state of nature $a$ was observed. Since a single animal could have been observed in multiple zones in a given season, $r^{s t}{ }_{a i j}$ represents the percentage of the total days of season $s$ that a caribou which had been observed in zone $i$ during the previous period spent in zone $j$ in year $t$ season $s$. (Note that if $s=1$, the previous period is the final season of year $t-1$ rather than $(t, s-1)$.) The calculated $r_{i j}^{s t}$ typically would differ among collared animals in a given year and season, as well as for the same animal observed across different years with the same seasonal state of nature. Therefore, to estimate the herd expected transition probability $p_{a i j}^{s}$, we calculated the weighted average of the $r^{s t}{ }_{i j}$ over the observed animal-seasons, using as weights the proportions to the time an animal was observed to have spent in zone $i$ the previous season. That is, if $d^{s-1, t}$ ain represents the proportion of total days of season $s$ that animal $n$ spent in zone $i$ during the previous period when the seasonal state of nature was $a$, the transition probability is

$$
p_{a i j}^{s}=\Sigma_{t} \Sigma_{n} d_{a i n}^{s-1, t} r_{a i j}^{s t} / \Sigma_{t} \Sigma_{n} d^{s-1, t} a i n
$$

For example, suppose a collared animal had spent 60 percent of the days of season 1 in 1999 in zone 1, and 40 percent of the days of season 2 in 1999 in zone 2. Suppose the same animal also had spent 40 percent of the days of season 1 in 2002 in zone 1, and 80 percent of season 2 that year in zone 2, when the same state of nature occurred as in season 2 of 1999. Suppose another animal had spent 20 percent of the days in season 1 of 2002 in zone 1, and had spent 20 percent of the days in season 2 in zone 2 that year. The three $r_{a 12}^{2 t}$ would be $0.4,0.8$, and 0.2 , while their respective weights, $d_{a 1 n}^{1 t}$, would be $0.6,0.4$, and 0.2 . The weighted average $p_{a 12}^{2}$ given by equation (A.2) would be $(0.24+0.32+0.04) /(0.6+0.4+0.2)=0.6 / 1.2=0.5$.

\section{Simulating the model}

Equations (A1.1) and (A1.2) define the expected distribution of animals over time. Simulating seasonal path-dependent herd-scale movements requires modeling two types of uncertainty: (1) 
uncertainty associated with the state of nature representing seasonal weather along with its ecological consequences, and (2) uncertainty associated with the movement of animals given the season and state of nature. To explain the simulation protocol, we start with the example of a single animal observed in an initial time period (0), corresponding to season $s-1$ in a simulation year. Let $x^{0}$ represent a row vector of length $k$ describing the position of the animal among the $k$ zones in that initial period. The animal will be observed in one of the $k$ zones -- for example, zone $i$-- that is, $x_{i}^{0}=1 ; x_{j}^{0}=0, j \neq i$. The model starts a new time step by randomly drawing one of two states of nature for time $t$ with a 50 percent probability. Suppose the state of nature (seasonal weather) in period 1 is revealed to be condition $c$. The probability that the animal will be observed in each of the $k$ zones in period 1 is given by the vector $p^{1}$ such that

$$
p^{1}=x^{0} P_{c}^{s}
$$

To accomplish the move to a new zone with probabilities specified by equation (A1.3), the model now draws another random number, $u$, from a uniform distribution between zero and one. Consider the cumulative probability matrix $P{ }^{*}{ }_{c}^{S}$ defined from $P_{c}^{S}$ such that each element $p{ }^{*}{ }_{c i j}$ of matrix $P{ }^{*}{ }_{c}$ equals the row sum from 1 to $j$ of $p_{c i j}^{s}$. That is,

$$
\begin{aligned}
& p^{* \mathrm{~s}}{ }_{c i j}=p^{s}{ }_{c i j},(j=1) ; \\
& p^{*{ }^{*}{ }_{c i j}}=p^{s}{ }_{c i j}+p^{* s}{ }_{c i, j-1},(1<j \leq \mathrm{k}) .
\end{aligned}
$$

For each row of $P^{* s}{ }_{c}$, one destination column $j$ will contain the largest $p^{*{ }_{c i j}^{s}}$ for which $p^{* s}{ }_{c i j} \leq u$. Define $Y_{c}^{1}$ as a square $k$ by $k$ matrix whose elements $y_{i j}^{1}=1$ if $j$ corresponds to the destination for row $i$ with maximum $p^{* s i j} \leq u$ :

$$
\begin{aligned}
& y_{i j}^{1}=1, \text { if } p^{*^{s}}{ }_{c i j}=\max _{j} p^{*_{c i j}^{s}} \mid\left(p^{*^{s}}{ }_{c i j} \leq u .\right) \\
& y^{1}{ }_{i j}=0, \text { otherwise. }
\end{aligned}
$$

Finally, the model moves the animal to a position in period 1 described by the vector $x^{1}$ :

$$
x^{1}=x^{0} Y_{c}^{t}
$$

The sequence is repeated for the next season corresponding to period 2, with a new random draw for the state of nature and a random move according to the season $s+1$ transition matrix associated with the newly revealed state of nature, and so on.

The model scales up from movement of a single animal to movement of the herd by defining a set of $n$ clusters of animals, each of size $m$. Each of the $m$ animals in a given cluster moves together among zones as if it were a single animal, according to the dynamics of equations (A1.3 through A1.6). While all the clusters use the same outcome for the seasonal state of nature in a given time step, each cluster has its own independent random draw for the vector $u$, used for random assignment to zones. The distribution of the herd among zones at time 1 is built up, therefore, from the sum over $n$ of $q_{n} x^{1}$. 
An example (Table A1.1) illustrates an example for one animal in a single time step: fall migration (August 8 - October 7). Table A1.1a shows the transition matrix, $P^{S}$, for its two possible climatic states, i.e., whether the first snowfall arrives early or late in the season, and Table A1.1b shows the associated cumulative probability matrix, $P^{* 5}$. Since animals were never observed in zones 7, 9, 10, 11 or 12 during the previous season (mid summer) those rows are omitted from the table. Assume that the animal was in the Chandalar Basin region (Zone 4) the previous season, and that fall snow came early that year. The model generates a random number uniformly distributed between zero and one: for example, 0.427 . It then goes to the zone 4 row of the 'Early snowfall' cumulative probability table (first row of shaded cells), to find the largest entry that does not exceed 0.427 (in this case, the third number, 0.107; the model moves the animal to zone 3 ). If fall snow had been late instead of early, the model would have used the late snowfall table and searched across row 4 until it found the value 0.359 , which would have kept the animal in zone 4.

Table A1.1 (a) Transition table for fall migration season (Aug 8-Oct 7) for two environmental conditions: early and late snowfall. (b) Cumulative probability table for model lookup. Shaded rows indicate the numbers used in the example.

\begin{tabular}{|c|c|c|c|c|c|c|c|c|c|c|c|c|c|c|}
\hline \multirow[t]{2}{*}{ (a) } & \multicolumn{14}{|c|}{ Normalized probability that caribou move into zone: } \\
\hline & From zone & 1 & 2 & 3 & 4 & 5 & 6 & 7 & 8 & 9 & 10 & 11 & 12 & 13 \\
\hline \multirow{8}{*}{ 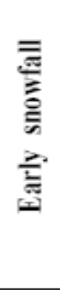 } & 1 & 0.018 & 0.342 & 0.081 & 0.450 & 0.027 & 0.027 & & & & & & & 0.054 \\
\hline & 2 & 0.038 & 0.221 & 0.198 & 0.189 & 0.247 & 0.064 & 0.004 & 0.002 & & & & & 0.038 \\
\hline & 3 & & 0.027 & 0.329 & 0.116 & 0.335 & 0.181 & & 0.011 & 0.001 & & & & \\
\hline & 4 & & 0.015 & 0.092 & 0.409 & 0.326 & 0.091 & & 0.060 & & & 0.007 & & \\
\hline & 5 & & 0.020 & 0.146 & 0.083 & 0.453 & 0.184 & 0.001 & 0.103 & 0.003 & & 0.007 & & \\
\hline & 6 & & 0.030 & 0.065 & 0.065 & 0.476 & 0.349 & 0.001 & 0.015 & & & & & \\
\hline & 8 & & & & & 0.500 & & & 0.500 & & & & & \\
\hline & 13 & & 0.224 & & 0.139 & 0.004 & & & & & & & & 0.633 \\
\hline \multirow{8}{*}{ 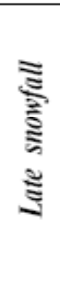 } & 1 & 0.002 & 0.191 & 0.107 & 0.179 & 0.356 & 0.079 & 0.002 & 0.019 & & & & & 0.065 \\
\hline & 2 & 0.005 & 0.170 & 0.129 & 0.225 & 0.343 & 0.089 & 0.004 & 0.025 & 0.001 & 0.001 & 0.001 & & 0.007 \\
\hline & 3 & & 0.006 & 0.160 & 0.058 & 0.507 & 0.206 & 0.002 & 0.047 & 0.010 & 0.001 & 0.004 & & \\
\hline & 4 & & 0.023 & 0.086 & 0.251 & 0.382 & 0.145 & 0.011 & 0.047 & 0.017 & 0.003 & 0.035 & & \\
\hline & 5 & & 0.003 & 0.119 & 0.134 & 0.494 & 0.118 & 0.011 & 0.086 & 0.017 & 0.003 & 0.016 & & \\
\hline & 6 & & 0.006 & 0.129 & 0.094 & 0.395 & 0.258 & 0.004 & 0.060 & 0.047 & & 0.007 & & \\
\hline & 13 & & & & & 0.136 & 0.011 & & & & & & & 0.852 \\
\hline & & 0.007 & 0.399 & 0.730 & 0.940 & 2.613 & 0.906 & 0.034 & 0.284 & 0.092 & 0.007 & 0.062 & & 0.924 \\
\hline
\end{tabular}

\begin{tabular}{|c|c|c|c|c|c|c|c|c|c|c|c|c|c|c|}
\hline b) & From zone & 1 & 2 & 3 & 4 & 5 & 6 & 7 & 8 & 9 & 10 & 11 & 12 & 13 \\
\hline \multirow{8}{*}{ 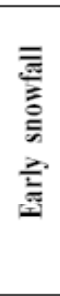 } & 1 & 0.018 & 0.360 & 0.441 & 0.892 & 0.919 & 0.946 & 0.946 & 0.946 & 0.946 & 0.946 & 0.946 & 0.946 & 1.000 \\
\hline & 2 & 0.038 & 0.259 & 0.457 & 0.646 & 0.893 & 0.956 & 0.960 & 0.962 & 0.962 & 0.962 & 0.962 & 0.962 & 1.000 \\
\hline & 3 & 0.000 & 0.027 & 0.356 & 0.472 & 0.807 & 0.988 & 0.988 & 0.999 & 1.000 & 1.000 & 1.000 & 1.000 & 1.000 \\
\hline & 4 & 0.000 & 0.015 & 0.107 & 0.516 & 0.842 & 0.933 & 0.933 & 0.993 & 0.993 & 0.993 & 1.000 & 1.000 & 1.000 \\
\hline & 5 & 0.000 & 0.020 & 0.166 & 0.249 & 0.701 & 0.886 & 0.887 & 0.990 & 0.993 & 0.993 & 1.000 & 1.000 & 1.000 \\
\hline & 6 & 0.000 & 0.030 & 0.094 & 0.159 & 0.634 & 0.984 & 0.985 & 1.000 & 1.000 & 1.000 & 1.000 & 1.000 & 1.000 \\
\hline & 8 & 0.000 & 0.000 & 0.000 & 0.000 & 0.500 & 0.500 & 0.500 & 1.000 & 1.000 & 1.000 & 1.000 & 1.000 & 1.000 \\
\hline & 13 & 0.000 & 0.224 & 0.224 & 0.363 & 0.367 & 0.367 & 0.367 & 0.367 & 0.367 & 0.367 & 0.367 & 0.367 & 1.000 \\
\hline \multirow{7}{*}{ 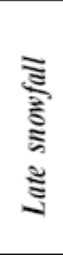 } & 1 & 0.002 & 0.193 & 0.300 & 0.479 & 0.835 & 0.914 & 0.916 & 0.935 & 0.935 & 0.935 & 0.935 & 0.935 & 1.000 \\
\hline & 2 & 0.005 & 0.175 & 0.305 & 0.530 & 0.873 & 0.962 & 0.966 & 0.991 & 0.992 & 0.993 & 0.993 & 0.993 & 1.000 \\
\hline & 3 & 0.000 & 0.006 & 0.166 & 0.224 & 0.731 & 0.937 & 0.939 & 0.986 & 0.995 & 0.996 & 1.000 & 1.000 & 1.000 \\
\hline & 4 & 0.000 & 0.023 & 0.109 & 0.359 & 0.741 & 0.887 & 0.898 & 0.945 & 0.962 & 0.965 & 1.000 & 1.000 & 1.000 \\
\hline & 5 & 0.000 & 0.003 & 0.122 & 0.256 & 0.750 & 0.867 & 0.878 & 0.964 & 0.981 & 0.984 & 1.000 & 1.000 & 1.000 \\
\hline & 6 & 0.000 & 0.006 & 0.135 & 0.229 & 0.624 & 0.882 & 0.886 & 0.947 & 0.993 & 0.993 & 1.000 & 1.000 & 1.000 \\
\hline & 13 & 0.000 & 0.000 & 0.000 & 0.000 & 0.136 & 0.148 & 0.148 & 0.148 & 0.148 & 0.148 & 0.148 & 0.148 & 1.000 \\
\hline
\end{tabular}


The transition tables determine movement of animals into the 13 large zones. To place each of the $m$ animals in a cluster into the 39 smaller hunting subzones, the model uses the results of the kernel analysis described in McNeil et al. (2005). That analysis calculated utilization density grids for the 16 seasonal condition combinations ( 8 seasons $\mathrm{x} 2$ conditions per season) from the same satellite collar dataset (McNeil et al. 2005: Table 2). We derived a conditional subzone transition matrix, $H_{a j}^{s}$, for the relevant season and climate driver from these McNeil et al. (2005) density grids. The elements of $H_{a j}^{s}, h_{a j z}^{s}$, express the probability that an animal will be found in subzone $z$, given assignment to the larger zone $j$. We calculated the conditional subzone cumulative probability table, $H^{* s}{ }_{a j}$, with elements $h^{* s}{ }_{a j z}$, as given by equation (A1.7):

$$
\begin{aligned}
& h^{*}{ }_{c j z}^{\mathrm{s}}=h_{c j z}^{s},(z=1) ; \\
& h^{*{ }^{s}{ }_{c j z}}=h_{c j z}^{s}+h^{* s}{ }_{c j, z-1},\left(1<z \leq g_{j}\right) .
\end{aligned}
$$

Once a cluster of animals moves to zone $j$ according to equations (A1.3-A1.6), the model draws a separate random number for each of the $m$ members of the cluster, looking this number up in the relevant $H^{* s}{ }_{a j}$ table of subzone cumulative probabilities to assign each animal in the cluster to one of zone $j$ 's $g_{j}$ subzones. The potential to simulate two hierarchical levels of random movement provides flexibility for modeling spatial heterogeneity of herd dynamics.

\section{Running the model and evaluating model results against empirical observations}

We ran 1,000 Monte Carlo simulations, each with 28 animals spanning a 19-year simulation period: June 1985 - May 2003, using historical seasonal environmental states (Figure A1.1). Observed calving distributions from June 1985 using (Griffith et al. 2002) initialized the model. Each model run moved 7 clusters of 4 animals apiece into one of the 13 large zones with seven random draws per season. Four additional random draws per season for each of the 7 groups assigned the 4 caribou within each cluster individually to subzones.

Figure A1.1. Environmental conditions by season and year used for historical simulation.

\begin{tabular}{|l|c|c|c|c|c|c|c|c|c|c|c|c|c|c|c|c|c|c|c|}
\hline Model year ${ }^{\mathrm{a}}$ & 85 & 86 & 87 & 88 & 89 & 90 & 91 & 92 & 93 & 94 & 95 & 96 & 97 & 98 & 99 & 00 & 01 & 02 & 03 \\
\hline Calving & & & & & & & & & & & & & & & & & & & \\
\hline Post-calving & & & & & & & & & & & & & & & & & & & \\
\hline Summer (A and B) & & & & & & & & & & & & & & & & & & & \\
\hline Fall (A and B) & & & & & & & & & & & & & & & & & & & \\
\hline Winter & & & & & & & & & & & & & & & & & & & \\
\hline Spring & & & & & & & & & & & & & & & & & & \\
\hline
\end{tabular}

${ }^{a}$ The eight seasons of a model year run from calving in calendar year $t$ through spring of calendar year $t+1$ (i.e., Calving in the first column represents June 1985, while Spring represents April/May 1986). Summer and Fall are each subdivided into two model seasons (see Table 3 for details). Sample sizes (number of animals collared) for each seasonal condition ranged from 41 to 93 .

Symbol legend:

Late snowmelt or snowfall, shallow snow Fast vegetation green-up

High insect abundance

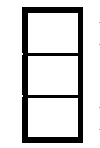
Early snowmelt or snowfall, shallow snow Slow vegetation green-up Low insect abundance 
We took the output of the 1,000 runs, and computed the $5^{\text {th }}$ percentile, $50^{\text {th }}$ percentile, $95^{\text {th }}$ percentile number of caribou in each of the 39 hunting subzones for each year-season, and also summed the total number of animals over all 1,000 runs. This sum represented a dynamic simulation of the distribution of 28,000 animals. Since the Porcupine Caribou Herd during this period averaged around 140,000 animals, multiplying by 5 provides an estimate of the actual expected total number of animals by subzone. Although the approach outlined above differs from that of computing density kernels, the simulated caribou abundance by subzone mimics what would be obtained from computing a conditional density kernel for each season, given the environmental state and the caribou distribution the previous season.

\section{Presencelabsence cross-tabulations with observed satellite collar location data}

To confirm that the model had been correctly parameterized and coded, we compared model simulation output with the original satellite location point data from which it was derived. Using GIS overlays, we compared the satellite collar data (19,509 individual location points) to the model output joined to subzone polygons. Next, we compared observed caribou locations (the satellite data) with predicted distributions (the model) for each season and year by subzone. This produced a dataset of 5,616 data points - 39 subzones by 8 seasons per year by 18 years - at different statistical thresholds: 5 percent, 50 percent, and 95 percent. (Although collar data spanned 19 years, no collars transmitted location data in 1996.)

We cross-tabulated the number of instances (i.e., the number of seasons by subzone and year) that model predictions and satellite locations agreed or disagreed. In this 'cross-tab' analysis there were four possible outcomes: (a) model predicted animals in the same subzone where caribou were observed (true positive: $+/+$ ); (b) model predicts no animals where no animals were observed (true negative: -/- ); (c) model predicts no animals where animals were observed (false negative: $-/+$ ); (d) model predicts animals where no animals were observed (false positive: $+/-$ ).

The cross-tabulations between the satellite locations and model output showed that the model generated results that were consistent with the original satellite collar locations. Table A1.2 summarizes the results of the cross-tab analysis. The top panel of the cross-tab analysis compares the satellite data with output from the $95^{\text {th }}$ percentile model run $(100=$ most animals in a subzone that year and season, $0=$ least). There were 2,856 cases ( 51 percent of 5,616 total subzone-seasonyears) in which the model predicted that caribou were absent (i.e., no caribou clusters in that subzone). In 73 (2.6\%) of these were cases, at least one satellite location was recorded, while the remaining 2,783 cases (97.4\%) had no satellite collars present. Hence, using a conservative model threshold for predicting caribou absence, there was a high correlation with the satellite data: the model rarely predicted caribou absence when satellite data showed presence.

Of the 1,164 cases in which at least one collared caribou was observed in a subzone-season-year, Table A1.2 showed that the model assigned caribou to the correct subzone in 1,091 cases (93.6\%), and failed to assign caribou in 73 cases (6.4\%). The 5th percentile threshold describes where the model almost always predicted caribou presence in a given subzone, season, and year. In the 5th percentile results, the model predicted that caribou were very likely to be present in only 1.4 (81) percent of subzone-season-year cases. In most of these cases (52, or 64.2\%), 
collared animals were also present in the observed dataset (Table A1.2). We concluded that both the 95th percentile and fifth percentile results from the model were fully consistent with the empirical observations from which they were derived.

Table A1.2. Cross-tabulation of simulated caribou distribution by observed satellite locations: 5616 subzone-seasons (39 subzones, 8 seasons per year, 18 years), percentiles indicate rank of simulation runs $(0=$ least predicted caribou in the subzone that season and year, $100=$ most)

\begin{tabular}{|c|c|c|c|c|c|}
\hline \multirow{2}{*}{$\begin{array}{c}\text { Percentil } \\
\text { run }\end{array}$} & \multicolumn{2}{|c|}{ Simulated caribou distribution } & \multicolumn{3}{|c|}{ Observed collared animals } \\
\hline & Model category & Comparison & No caribou (-) & At least one $(+)$ & TOTAL \\
\hline \multirow[t]{6}{*}{$95^{\text {th }}$} & No caribou (-) & Subzone-seasons & 2783 & 73 & 2856 \\
\hline & & $\%$ of model category & 97.4 & 2.6 & 100 \\
\hline & & $\%$ of total & 49.6 & 1.3 & 50.9 \\
\hline & At least one $(+)$ & Subzone-seasons & 1669 & 1091 & 2760 \\
\hline & & $\%$ of model category & 60.5 & 39.5 & 100 \\
\hline & & $\%$ of total & 29.7 & 19.4 & 49.1 \\
\hline \multirow[t]{6}{*}{$50^{\text {th }}$} & No caribou (-) & Subzone-seasons & 4020 & 586 & 4606 \\
\hline & & $\%$ of model category & 87.3 & 12.7 & 100 \\
\hline & & $\%$ of total & 71.6 & 10.4 & 82.0 \\
\hline & At least one $(+)$ & Subzone-seasons & 432 & 578 & 1010 \\
\hline & & $\%$ of model category & 42.8 & 57.2 & 100 \\
\hline & & $\%$ of total & 7.7 & 10.3 & 18.0 \\
\hline \multirow[t]{6}{*}{$5^{\text {th }}$} & No caribou (-) & Subzone-seasons & 4423 & 1112 & 5535 \\
\hline & & $\%$ of model category & 79.9 & 20.1 & 100 \\
\hline & & $\%$ of total & 78.8 & 19.8 & 98.6 \\
\hline & At least one $(+)$ & Subzone-seasons & 29 & 52 & 81 \\
\hline & & $\%$ of model category & 35.8 & 64.2 & 100 \\
\hline & & $\%$ of total & 0.5 & 0.9 & 1.4 \\
\hline
\end{tabular}

These tests provided confidence that the model did not have internal coding or parameterization errors that would obviously invalidate it. The tests were insufficient by themselves to evaluate the model, however, since the tests and model were derived from the same original data.

\section{Literature Cited}

Griffith, B., D. C. Douglas, N. E. Walsh, D. D. Young, T. R. McCabe, D. E. Russell, R. G. White, R. D. Cameron, and K. R. Whitten. 2002. The Porcupine caribou herd. Pages 837 in D. C. Douglas, P. E. Reynolds, and E. B. Rhode, editors. Arctic Refuge coastal plain terrestrial wildlife research summaries. U. S. Geological Survey, Biological Resources Division.

McNeil, P., D.E. Russell, D.B Griffith, A. Gunn \& G.P. Kofinas. 2005. Where the wild things are: Seasonal variation in caribou distribution in relation to climate change. Rangifer Special Issue 16:51-63. 